\title{
Taller RAD cultura del diseño de la \\ mano con el sector productivo
}

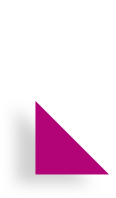




\section{"Generar una cultura y reconocimiento del diseño en las empresas. Concientizar y dimensionar la función y capaci- dades del diseño en el que hacer empresarial a través de un ejercicio de articulación Academia-Industria". (RAD, 2017).}

\section{OBJETIVO}

Se desarrolla como una práctica social y de innovación a través de la cooperación entre las universidades Nacional, Autónoma de Colombia, Jorge Tadeo Lozano, Fundación Universitaria los Libertadores, Areandina y SENA, con los sectores productivos, en este caso, representados por la Cámara de Comercio de Bogotá y las empresas vinculadas al Cluster de calzado, cuero y marroquinería, y al Cluster de Prendas de vestir.

Precisamente dentro de las iniciativas que desarrolla la Cámara de Comercio de Bogotá con los diferentes Clusters está el "generar escenarios neutrales, en donde líderes empresariales y representantes del Gobierno y de la academia, definen una visión conjunta y de trabajo en equipo para alcanzar el propósito acordado" (CCB, 2017).

Taller RAD se ha destacado por ser un modelo integral de diseño donde directivos y docentes que hacen parte de la Asociación le han apostado a fortalecer las competencias del futuro profesional a través de la integración de espacios y temáticas en las diferentes instituciones con el reconocimiento de los procesos productivos propios en cada empresa.

A partir de los acuerdos establecidos por parte de las instituciones, se programan diferentes actividades y charlas que son realizadas por los docentes e invitados al taller para profundizar en temas como: inteligencia de consumo, códigos culturales, sistema moda, informes sobre tendencias, identidad visual, diseño de producto, visual merchandising, entre otros. 


\section{INNOVACIÓN TENDENCIAS INDUSTRIA}

Los grupos de trabajo están integrados por estudiantes de cada institución y diferente especialidad. Inicialmente el objetivo es que apropien los conceptos más importantes sobre la cadena productiva y sus diferentes eslabones: materia prima, producción, comercialización y consumo. También se les orienta sobre las metodologías e instrumentos de diagnóstico que son pertinentes para su posterior aplicación con las empresas.

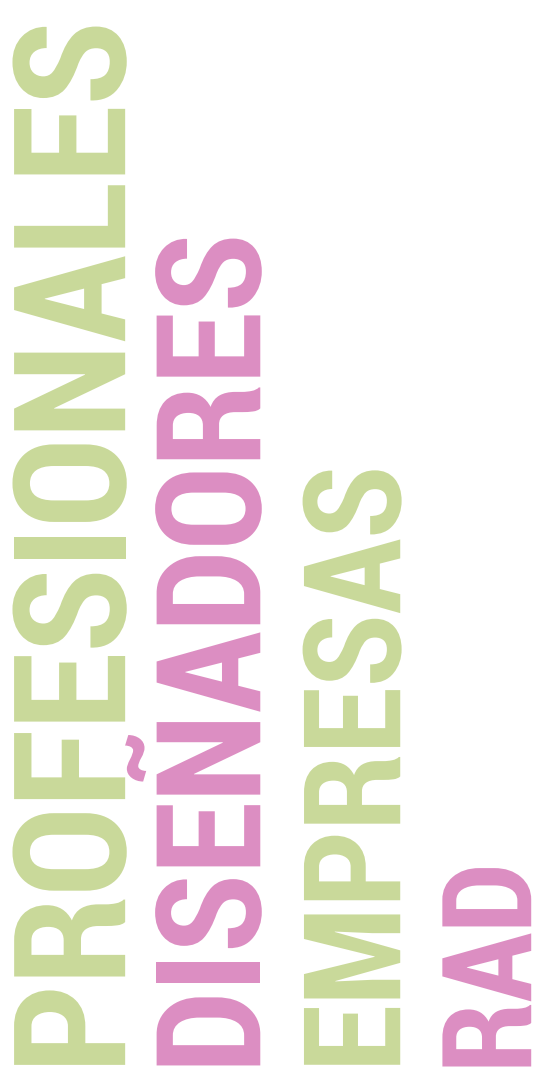

Entender el diseño como un sistema, reconocer y respetar el conocimiento y experiencia de cada uno es fundamental para cumplir con los objetivos del taller, para facilitar esta dinámica los estudiantes desarrollan un trabajo de Co-Diseño con el empresario que le va a permitir reconocer la situación actual de su empresa, hacerlo participe del proceso creativo, definir su usuario y las estrategias para que desde cada especialidad se proyecten planes de mejora e innovación. 


\section{UNIVERSIDAD NACIONAL}

\section{UNIVERSIDAD AUTONOMA DE COLOMBIA JORGE TADEO LOZANO}

Es importante destacar la apertura y generosidad que han demostrado los empresarios para acceder a trabajar en equipo con los estudiantes, orientándolos con paciencia desde su propia historia de emprendimiento.

Interactuar con cada una de las universidades y compartir metodologías con los compañeros docentes y empresarios ha sido una experiencia muy significativa. También es importante destacar el trabajo realizado por los estudiantes de diseño de modas y de diseño gráfico de Areandina Bogotá, quienes han obteniendo unos resultados satisfactorios, con un alto nivel académico y con grandes posibilidades de implementación por parte de las empresas vinculadas al taller.

\section{FUNDACIÓN UNIVERSITARIA LOS LIBERTADORES

